\title{
GIS and remote sensing techniques in Controlled Environment Agriculture: A review
}

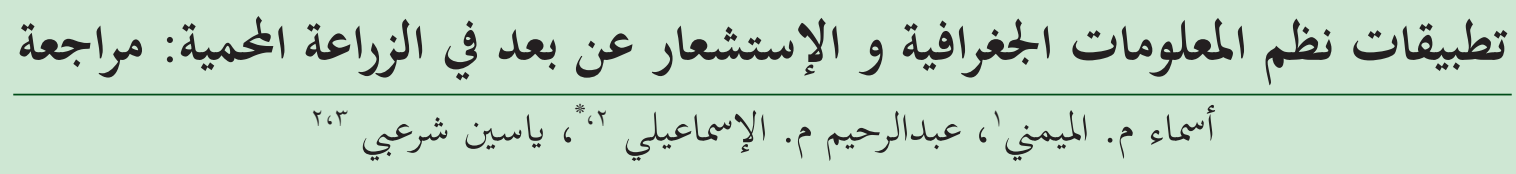

AbStract. Geographic Information System (GIS) and Remote Sensing (RS) are useful tools in environmental monitoring, evaluation and analysis for various sectors including agriculture. This paper reviews the applications of GIS, RS and the integration of both techniques in the agricultural field, in general, and Controlled Environment Agriculture (CEA), in particular. More emphasis is given to their applications in arid areas and Oman is taken as a case study. GIS techniques have been used in the mapping of soil and water quality, spatial assessment for water quantity stress, land suitability, pest and disease distribution of crops as well as delineating and generating database management systems (DBMS) for protected cultivations. In Oman, GIS was only employed to analyse the spatio-temporal dynamics of land use changes as affected by external factors and greenhouses as an example in northern part. RS was also utilised to map the changes in land cover and their uses, detect and map soil salinity, and monitor agricultural droughts. In CEA, RS was utilised for mapping, detection and classification of greenhouses through aerial images and satellites. In Oman, negligible study was documented on the use of RS techniques in the CEA field. The integration of both techniques has proven its capability in mapping, evaluating and managing natural resources and greenhouse distribution and generating database management system in agriculture and CEA fields. Sophisticated geostatistical analysis models based on Multi-criteria analysis using Fuzzy-logic and Analytic Hierarchy Process could be a good platform for trade-off analysis for land suitability analysis and optimal location of CEA in challenging agriculture like Oman.

KEYWORDS: GIS; Remote sensing; greenhouse; database management system

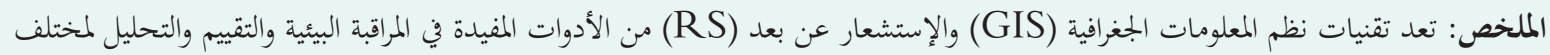

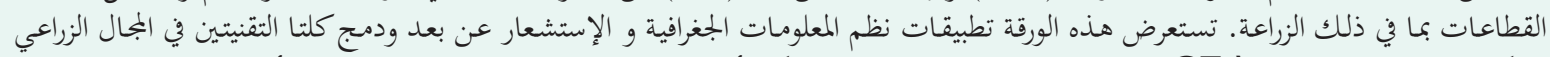

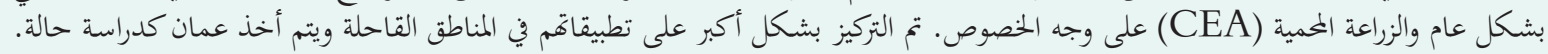

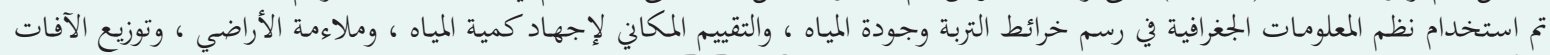

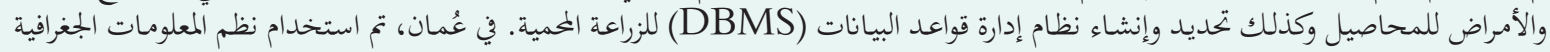

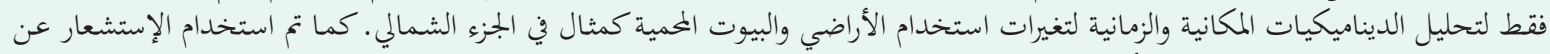

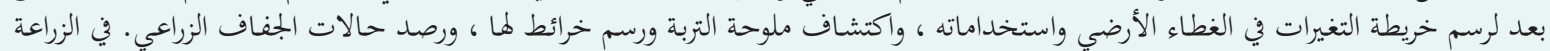

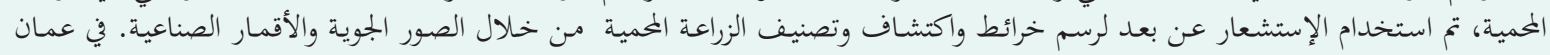

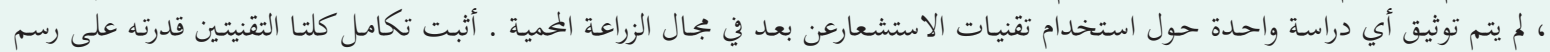

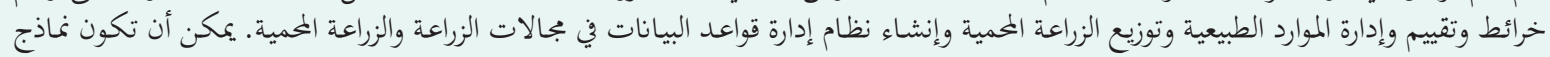

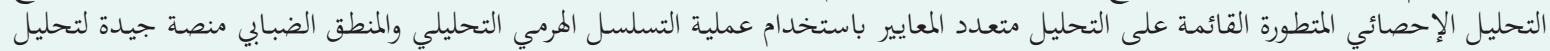

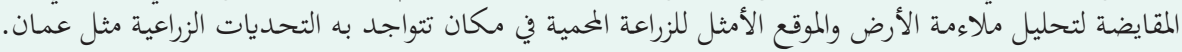

$$
\begin{aligned}
& \text { الكلمات المفتاحية: نظم المعلومات الجغرافية، الإستشعار عن بعد، البيت المحمي، نظام ادارة قواعد البيانات. }
\end{aligned}
$$

\section{Introduction}

$\mathrm{I}$ $\mathrm{n}$ arid and semi-arid regions, high temperatures and water scarcity are the two major constraints for agriculture development and sustainability (Al-Ismai-

Abdulrahim M. Al-Ismaili 2,*( $(\checkmark)$ abdrahim@squ.edu.om; ams.ismaili@gmail.com, 'Department of Soils, Water and Agricultural Engineering, Sultan Qaboos University, Sultanate of Oman, ${ }^{2}$ Department of Geography, Sultan Qaboos University, Sultanate of Oman, Email: yassine@squ.edu.om, ${ }^{3}$ Center for Environmental Studies and Research, Sultan Qaboos University, Sultanate of Oman li and Jayasuriya, 2016). Greenhouses are considered a sustainable option for crop production in harsh climatic conditions (Helmy et al., 2013; Kumar et al., 2009) through providing favourable microclimate for plants, extending the cropping season and achieving year-round production. Controlled Environment Agriculture (CEA) term refers to a group of agricultural systems including screenhouses, greenhouses, shade-houses and aquaponics (Al-Ismaili et al., 2017). The total area under plastic greenhouse covers has rapidly grown to reach more than 500,000 ha around the world (Agüera and Liu, 2009). 
However, this rapid growth of CEA should be monitored and mapped for better understanding and planning for the development and management of natural resources, which could be achieved using Geographic Information System (GIS) and RS (Remote Sensing) techniques.

GIS is a professional computer system that manipulates spatial and non-spatial data to present them in a simple illustrative manner on the map (Soomro, 2015). It links the tabular (database) information with their respective locational (Spatial) coordinates for better visualization. In addition, it has a unique capacity with spatial data in terms of collection, storage, management, conversion, analysis, modelling and display as it performs these functions in a very organised way (Davis, 1996). GIS tools and techniques are very helpful and beneficial in several fields including geography, computer science, environmental science, agriculture, forest, food, entertainment, banking, health services and manufacturing (Soomro, 2015).

$\mathrm{RS}$ is an art of acquiring information about an object or event on earth's surface, ocean or atmosphere using remote sensors (e.g. special cameras, radars and digital scanners) (Bhatta, 2011; Wang and Weng, 2013). Buildings, soils, water and vegetation are examples of sensing/observing objects at distant (remote) places which are investigated by scientists (Campbell and Wynne, 2011). RS has several distinguished advantages, such as observation of a broad area at one time (spatial) as well as observing the areas for long periods (temporal). Another advantage is the possibility to collect data from places that are geographically or politically inaccessible without any distortions (Bhatta, 2011; Wang and Weng, 2013). The user can benefit from the results of RS in a variety of applications such as ecosystems, natural landscapes, hydrology, urban planning and agriculture.

Usery et al. (1995) mentioned that advanced technologies such as GIS and RS are used to collect and handle spatially referenced data, perform spatial analysis and decision-making for factors related to geography in order to solve problems in planning and management (Parthasarathy, 2010; Soomro, 2015). Using interrelationships between geography, location and people in GIS makes it possible to take decisions aiming to improve the living on earth (Soomro, 2015). RS and GIS are very beneficial techniques to store, operate and quantitatively evaluate the soil sustainability and capability for various practices (Saleh et al., 2015).

\section{Applications of GIS in Agriculture}

In agricultural field, GIS can be used for a small scale areas like a single farm to a large scale areas like the globe (Wilson, 1999). The basic of success and profitability of any farm is to balance between inputs and outputs (Parthasarathy, 2010). GIS tools are beneficial to owners of agricultural farms by visualising the environmental parameters and workflows within their farms. These tools enable them to handle the agricultural spatial data, which are collected through mobile devices, in investigating their farm conditions and evaluating their effects on the wellbeing of their farms (Soomro, 2015).

Jayasuriya et al. (2014) presented the use of GIS in mapping the levels of soil compaction by heavy-load vehicles and the moisture content distribution of Rhodes grass to reach the best tillage and irrigation management. Results showed an inverse relationship between Rhodes grass growth and soil compaction levels. Sadat-Noori et al. (2014) worked on GIS and Water Quality Index (WQI) to assess and examine the spatial distribution of ground-water quality of Saveh-Nobaran aquifer in Iran. The major cations and anions $\left(\mathrm{Ca}, \mathrm{Mg}, \mathrm{Na}, \mathrm{HCO}_{3}\right.$, $\mathrm{SO}_{4}, \mathrm{Cl}$, and TDS), $\mathrm{EC}, \mathrm{pH}$ and hardness of ground-water samples were analysed and documented. Using GIS, maps of the aforementioned parameters were created using Kriging method. Figure 1 shows the WQI map of the selected aquifer. For the WQI assessment, they reported that $65 \%$ of samples were under three categories of drinking water qualities; very poor, poor and unsuitable. The amalgamation of GIS and WQI method was very effective and can help for better decision making. In another study, knowledge-base model was built in GIS environment to assess the supplementary irrigation in rain-fed agricultural watersheds in India (Reshmidevi et al., 2010). The model used the empirical information of land suitability for crops, irrigation practices and the hydrological models to improve the supplementary irrigation in the watershed. It was found that this model could be implemented to estimate the irrigation requirements based on rainfall conditions.

Land suitability analysis is necessary for agricultural planning and sustainability. GIS can also aid farmers to determine the preference areas for crop cultivation as well as to manage pests and increase the profit during harvesting (Soomro, 2015). Bhagat et al. (2009) used GIS to analyse land suitability for cereal production in Himachal Pradesh, India. The geo-referenced data (climate, elevation, soil and land cover) with potential production were fed to GIS. The resulted maps delineated suitable lands for growing cereals in the study area. For agricultural sustainability, GIS showed that small agricultural lands can be merged efficiently together. In Turkey, a study of land suitability for fruit growing using GIS was done by Yarilgac (2012). Similarly, Chiranjit and Kishore (2016) reviewed GIS applications on land suitability evaluation for agricultural crop selection using different approaches such as Fuzzy logic, Multi-Criteria Evaluation (MCE) and Analytic Hierarchy Process (AHP) within GIS environment. The MCE approach is one of the land assessment tools used for selecting the proper factors from a large number of factors and thus, giving the best solutions and finding alternatives for decision making (Gastli and Charabi, 2010; Hedia and Elkawy, 2016; Olaniyi et al., 2015). The combination of MCE within GIS environment gives a strong support for decision makers and researches. Hedia and Elkawy (2016) 


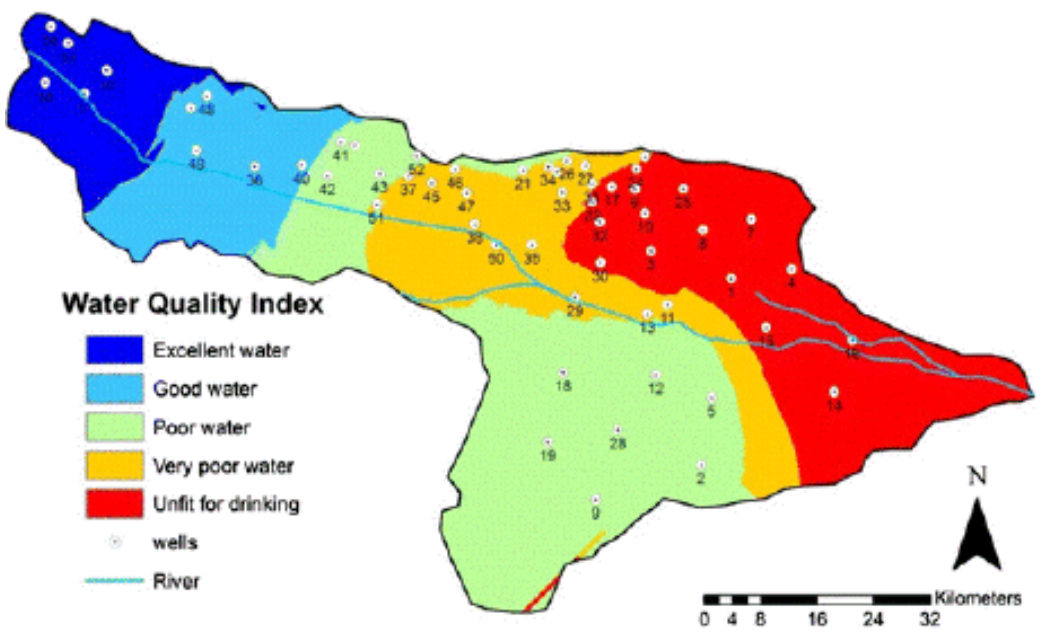

Figure 1. The spatial distribution of Water Quality Index (WQI) in Saveh-Nobaran aquifer in Iran (Sadat-Noori et al. 2014).

studied the assessment of land suitability for agricultural uses in Egypt by means of MCE within GIS. (Chivasa et al., 2019) evaluated the land suitability for maize production (Zea mays L.) with aid of GIS, AHP and MCE in Zimbabwe. Different thematic maps such as rainfall, soil type and slope were ovleraid in GIS environment. Results found that there was a significant posituve correlation between maize yield and classes of land suitability $\left(R^{2}=0.63-0.85\right)$. This method was effective and recommended to use it as a tool for decision making for maize placement in the country. Many researches have used the integration of AHP with GIS to assess land suitability (Mishra et al., 2015; Romano et al., 2015; Uyan, 2013)

Manyong et al. (2008) described the benefits of GIS techniques in disease and pest control particularly in predicting, monitoring and managing the spread of Xanthomonas wilt (BXW) in banana (Musa spp.). Similarly, a study on the spatial analysis of Lettuce Downy Mildew were conducted in USA (Wu et al., 2001). In another application, GIS was employed to map the agricultural plastic waste in Greece (Hiskakis et al., 2007).

In Oman, the use of GIS in agricultural-related applications was recently introduced. To date, several studies were conducted to measure the soil and water qualities using GIS. Jamrah et al. (2008) evaluated ground-water vulnerability using DRASTIC method in ArcGIS. DRASTIC stands for seven parameters; D: depth to groundwater, R: net recharge, A: aquifer media, C: hydraulic conductivity of the aquifer, S: soil media, I: impact of vadose zone and T: topography or slope. This study covered the period between 1994 and 2004 for Barka, North Al-Batinah Governorate. A number of seven DRASTIC layers were generated and the resulted maps revealed that the northern and central parts of Baraka were highly affected by contaminants compared to the southern part (Fig. 2).
Al-Barwani and Helmi (2006) studied seawater intrusion for the coastal aquifers between As' Seeb and As' Suwaiq cities for the years 1984-2005 (Figure 3). Using GIS, geographical locations of wells and their water salinity (EC) values were created on the map. The EC data were recorded from regular field measurements undertaken by the Ministry of Regional Municipalities and Water Resources. The salinity zones were delineated for all areas between the two cities. Results showed a $7 \%$ decrease in land with suitable water for agricultural purposes between 2000 and 2005. Also, they reported that seawater intrusion in Barka city has moved $12 \mathrm{~km}$ inland over the same period. GIS techniques have been used also for spatial assessment of water quantity stress across the Sultanate of Oman (Al-Awadhi and Mansour, 2015). Results presented significant variations in water quantity stress across the governorates. Also, seasonal variations in water supply and drought severity were the most important predicators for water quantity risk. In another study, Behrendt et al. (2015) investigated the distribution and diversity of banana (Musa spp.) in Wadi Tiwi, Oman. The spatial distribution of different banana cultivars is depicted in Figure 4.

Al-Habsi (2015) studied GIS-linked Computer Simulation Model for Wheat seed emergence predication in Oman. The study showed the best locations for wheat production in Oman through linking Simulation Model with Numerical Weather Predication Model (NWPM) in GIS environment. The model was used to predict time of emergence based on soil temperature, water potential and planting depth (Figure 5). In renewable energy sector, a study was done to investigate the best locations to build large Photovoltaic system (PV) using MCA (Multi-criteria analysis) in GIS environment in Al-Batinah farms, Oman (Gastli and Charabi, 2010). This will be beneficial to exploit the solar energy in Oman and implement large PV plants. It can be source of energy inside farms. 


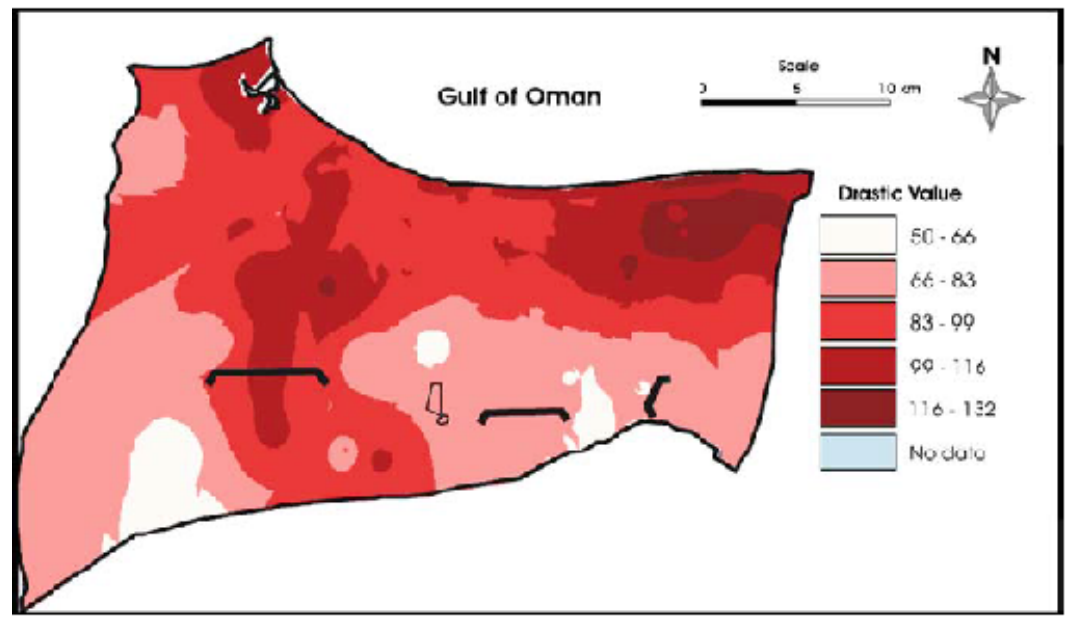

Figure 2. DRASTIC values for Barka in 2004 (Jamrah et al.. 2008).

\section{Applications of GIS in CEA}

Very few studies were reported on the applications of GIS in the field of Controlled Environment Agriculture (CEA). Matsuoka et al. (2015) studied the use of GIS and developed Monte Carlo method to simulate the collection of catch crops (e.g. dent corn) from greenhouses to collection stations in Kochi Prefecture in Japan. The study also estimated the yield production and carbon emissions from the transportation of catch crops. Using the results from the above investigations, potential ways to reduce groundwater contamination and conserve agricultural resources were explored. Results revealed that the total collected fresh weight of catch crops was 67,900 tons and $70 \%$ of production came from central plains of the study area where the cluster of greenhouses was more. GIS maps clearly illustrated that eggplant was the dominant crop in the eastern part and cucumber was the dominant crop in the western part (Figure 6).

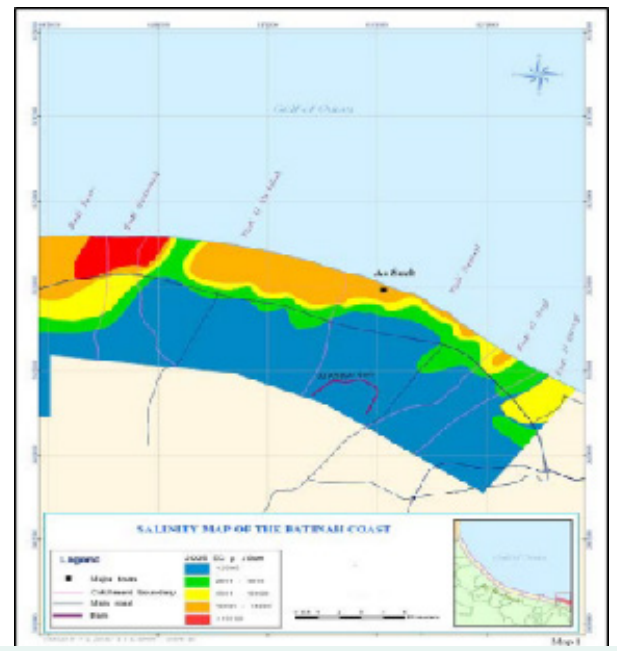

Figure 3. Salinity Zones in As' Seeb (Al-Barwani and Helmi 2006).
The combination of the developed method and GIS were easy and multilateral in solving collection and transportation problems. Crifasi et al. (2002) reported the use of GIS as a Data Base Management System (DBMS) for protected cultivations in Marsala town, western Sicily, Italy. The study covered an area of about 3,588 ha having 2,607 greenhouses (Figure 7). The distribution of greenhouses and their floor area were recorded. The study emphasised the capability of GIS to precisely determine greenhouse sizes and to handle, organise and administer large amounts of data in a quick and simple manner.

In Oman, there was only one study on the use of GIS in CEA. Deadman et al. (2016) studied the spatio-temporal dynamics of land use changes affected by external pressures and considered greenhouses as an example in northern Oman. This study considered GPS coordinates of greenhouses for five years; 2001, 2002, 2003, 2004 and 2009. Results revealed that greenhouse density was

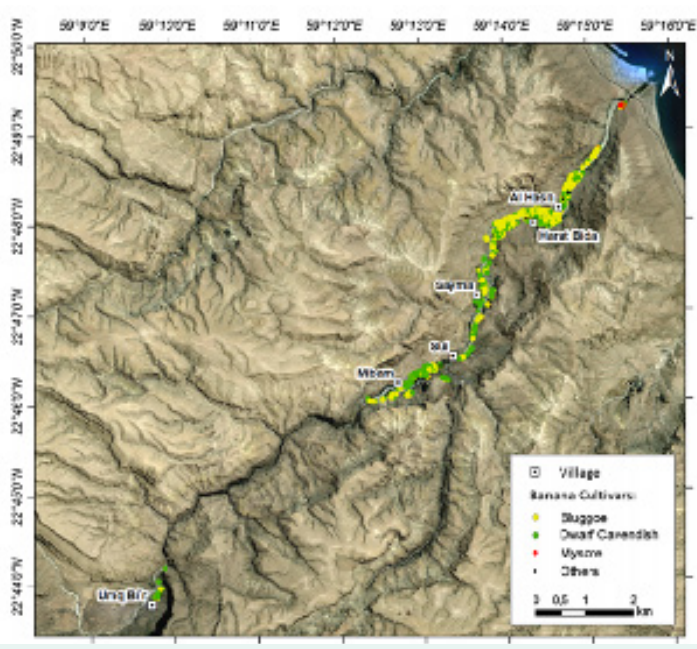

Figure 4. Geographical Locations of Musa spp. in the study area (Behrendt et al., 2015). 


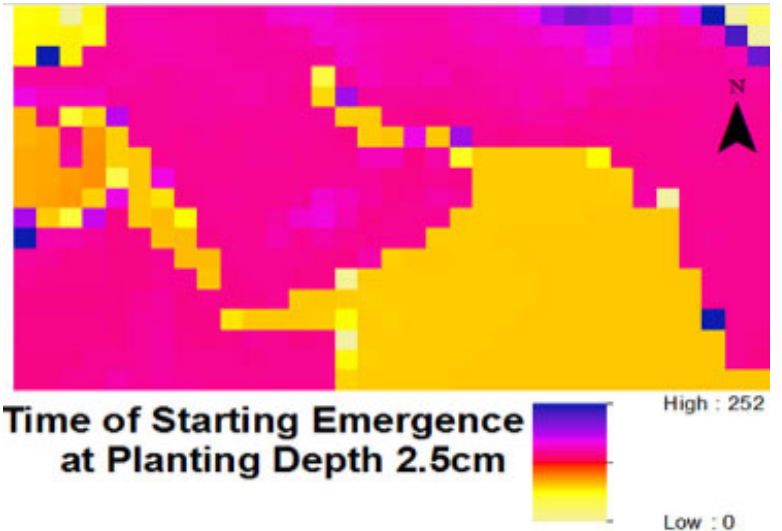

Figure 5. A raster map shows the time (days) of emergence at $25 \mathrm{~mm}$ planting depth (Al-Habsi, 2015).

increasing with increasing distance from the coastline (i.e. decreasing groundwater salinity). Barka city was the most affected by the increase in groundwater salinity and so, $57.8 \%$ of all abandoned farms in Al-Batinah governorates were in Barka (Figure 8). New and large farms were developed away from high levels of groundwater salinity and away from urbanised areas. Because this study did not cover the whole country, a more comprehensive study is necessary to investigate the factors affecting the spatio-temporal distribution of greenhouses in Oman.

\section{Applications of RS in agriculture}

Remote sensing (RS) is progressively used in a variety of agricultural applications such as soil salinity which is a severe environmental problem particularly in arid and

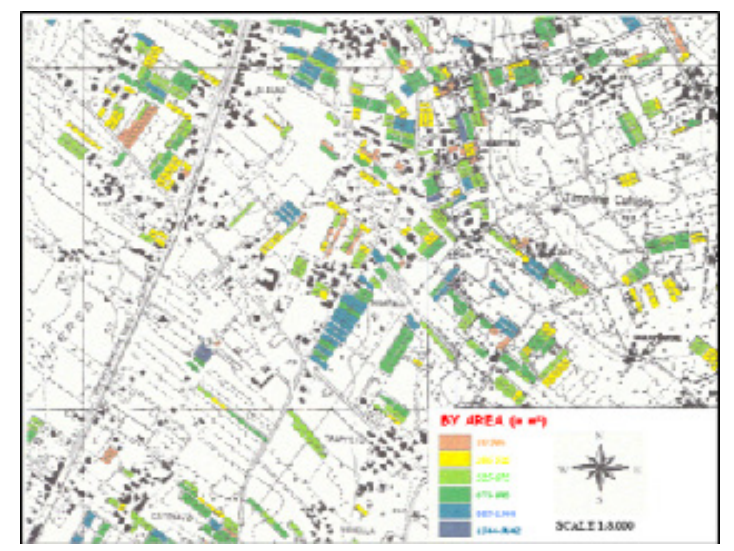

Figure 7. Distribution of greenhouses by area (m2) (Crifasi et al., 2002).

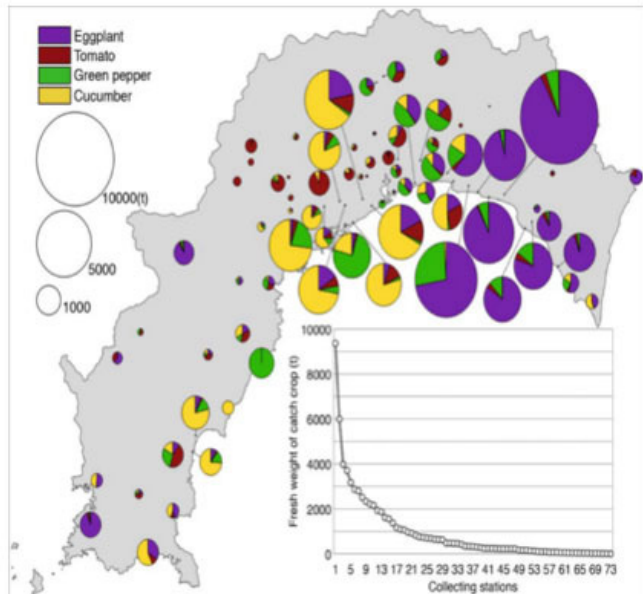

Figure 6. The cultivated area in proportions with four produced catch crops (Matsuoka et al., 2015).

semi-arid regions (Sahoo et al., 2015). RS techniques are professional, more informative and faster than traditional methods used in detecting soil salinity (Al-Mulla, 2010; Allbed and Kumar, 2013). Additionally, they have a capability in delineation, mapping and assessment of this problem. Alavipanah and Goossens (2001) studied the relationship between soil salinity and data obtained from Landsat TM and MSS. In another study, Allbed et al. (2014) described the use of IKONOS satellite imageries to assess the soil salinity using vegetation and soil salinity indices in a region dominated with date palm trees in Al-Hassa Oasis, Saudi Arabia. Three sites were selected within the study area and field measurements were under taken. Remotely sensed data were used to extract the Soil-Adjusted Vegetation Index (SAVI) and 12 soil

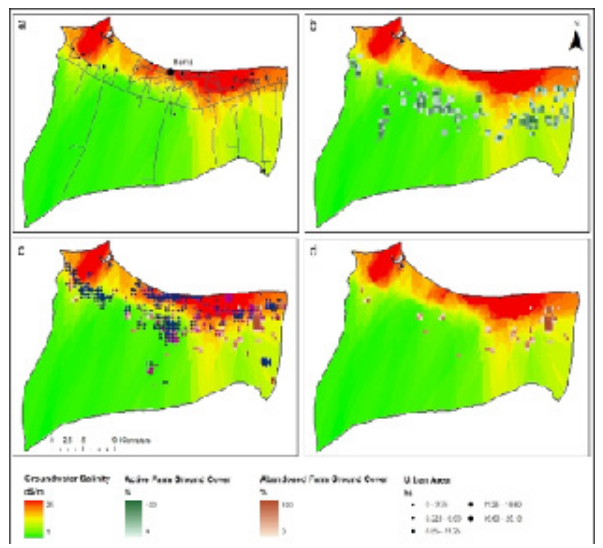

Figure 8. : Barka map displays levels of groundwater salinity related to active, abandonment ground cover and urban area (Deadman et al., 2016). 
salinity broadband indices. Results showed that soils of Al-Hassa Oasis were highly saline $(\mathrm{EC}>16 \mathrm{dS} / \mathrm{m})$. This salinity level was indicated with a higher spectral response in the visible and NIR range compared to the other salinity levels (Figure 9). However, other levels of soil salinity differed within the three sites due to human-induced or environmental factors such as: poor quality of irrigation water, unbalanced agricultural practices and poor drainage. The most beneficial indices for assessing based on temperature data for land surface, Normalized Difference Vegetation index (NDVI) and precipitation data from selected satellites for monitoring agricultural drought. On the other hand, Tenkorang and Lowenberg-DeBoer (2008) reviewed the potential of using RS to improve farm profits such as optimizing the use of fertilizers and pesticides.

In Oman, Al-Mulla (2010) highlighted the use of RS in mapping soil salinity. He mentioned that salinity is a dy-

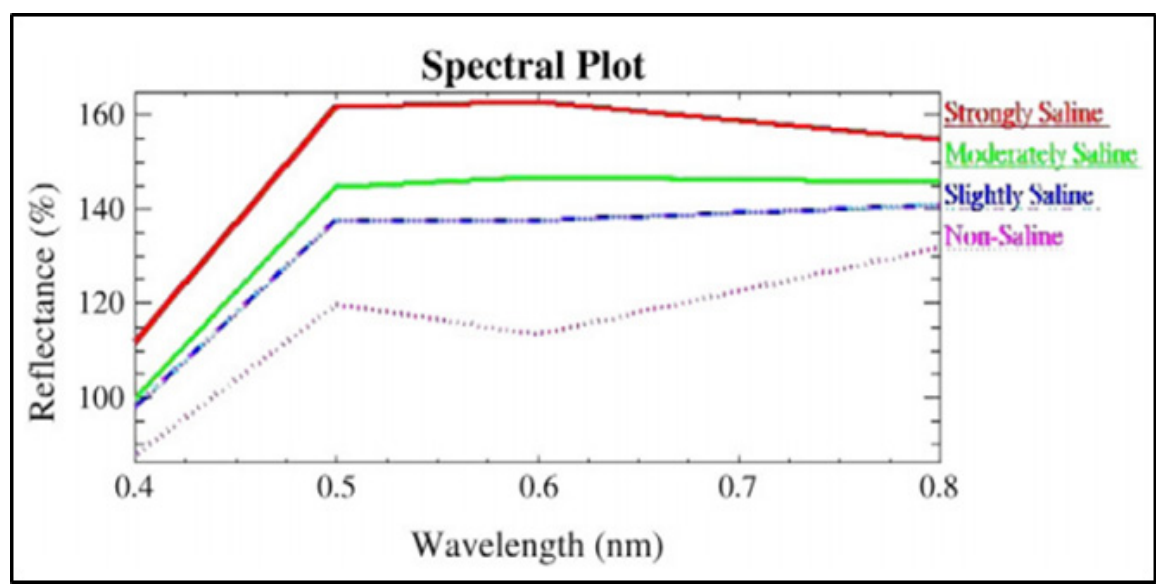

Figure 9. Soil spectral reflectance of Al-Hassa Oasis (Allbed et al., 2014).

soil salinity in areas dominated by date palm were SAVI, NDSI and SI-T that were extracted from the IKONOS.

A similar study was done using IKONOS satellite images and Landsat Multi Spectral Scanner (MSS) to detect crop reflectance, soil salinity levels and salinity impact on crop yield (Elhaddad and Garcia 2006). In another study, Alhammadi and Glenn (2008) studied SAVI to detect the health of date palms and greenness change of vegetation in the eastern part of United Arab Emaciates. SAVI was examined from Landsat Thematic Mapper (TM) and Enhanced Thematic Mapper Plus (ETM+) images for three different sites: Fujairah, Hatta and Kalba in 1987 and 2000. Additionally, field measurements were taken for ground-truthing. Results revealed that in Hatta, there was a reduction in vegetation greenness and healthy conditions yet the overall agricultural land area increased (Fig. 10). Salt-affected soils were identified using the SAVI values which decease with the rise in soil salinity. The study confirmed that a special attention should be given in monitoring and managing soil salinity problem to keep date palm trees productive. RS is also used to detect vegetative covers in forest vegetation using Vegetation Indices, VI (Jinguo and Wei, 2004). Dawbin and Evans (1988) reported some RS techniques for digital crop classification using Landsat data for Australian environment. For arid and humid regions, Rhee et al. (2010) proposed a new drought index called Scaled Drought Condition Index (SDCI) which is namic process which affected large areas in Oman. The vegetation abundance in the vicinity of Sultan Qaboos University in Muscat was studied using RS by Rajendran et al. (2016). On the other hand, Harris (2003) evaluated agricultural land changes using Landsat MSS in 1978 and Landsat Enhanced Thematic Mapper (ETM) data in 2001 (Fig. 11). The study was conducted in Khaburah and Sohar cities on the coastal line of Al-Batinah. Field work was done to support earth observation data for 1979 and 2001. The change in agricultural lands was estimated from environmental change maps that were derived from supervised and unsupervised classifications. The study concluded that the change in agricultural areas was clear and considerable in the study period due to the growing income since 1970, i.e. fast urbanization.

\section{Applications of RS in the CEA}

In recent years, rapid growth of plastic greenhouses took place and the total land area under plastic greenhouses reached more than 500,000 ha worldwide (Agüera and Liu, 2009). Mapping and detection of greenhouses by means of RS could be a challenging task (Aguilar et al., 2014; Aguilar et al., 2015; Tarantino and Figorito, 2012). Aguilar et al. (2014) studied the classification of greenhouses in Cuevas del Almanzora of Almeria, Spain, using Object-Based Image Analysis (OBIA) for two high resolution stereo images of GeoEye-1 (GE1) and WorldView-2 (WV2), (Figure 12). In the eastern part of Alme- 

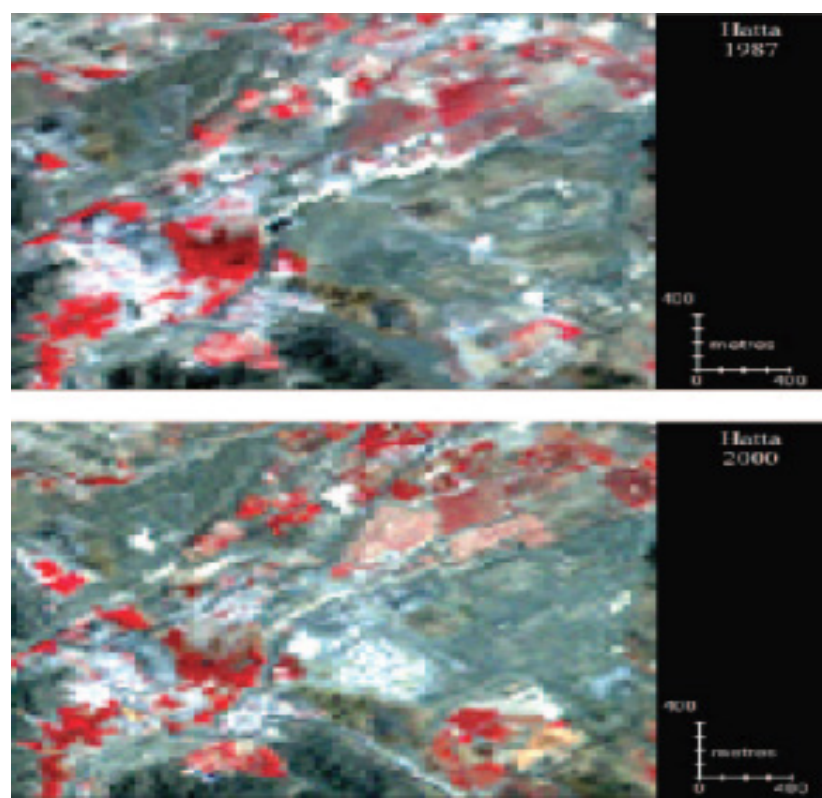

Figure 10. False colour composite images (red, layer 4; green, layer 3; and blue, layer 2) for Hatta area for 1987 (top) and 2000 (bottom). Red colour represents vegetation (Alhammadi and Glenn, 2008).

ria, Spain, another mapping of plastic greenhouses was produced using texture analysis to improve per-pixel classification from other high resolution satellite images which were QuickBird and IKONOS (Figure 13), (Agüera et al., 2008). Similarly, mapping of plastic covered vineyard using true colour aerial data (Very High Spatial Resolution) was examined in the Apulia Region (Italy) (Tarantino and Figorito, 2012). The object-based classification method from aforementioned data were developed for testing eight locations in the study area. The overall accuracy of the method used for mapping areas was about $90 \%$. In another study, Yang et al. (2017) developed a new spectral index for mapping plastic greenhouses through medium spatial resolution satellite images in China. RS approaches were also utilized to study the spatial and temporal patterns of greenhouses and the factors driving these changes between 2000 and 2015 in Shouguang City, China (Yu et al., 2017).

Arcidiacono and Porto (2010a) investigated the classification of crop-shelter using RGB aerial images. Similar study was done for the classification of crop shelter through processing of digital images in Italy (Arcidiacono and Porto, 2007). Aguilar et al. (2015) identified, for the first time, the horticultural crops that were grown under

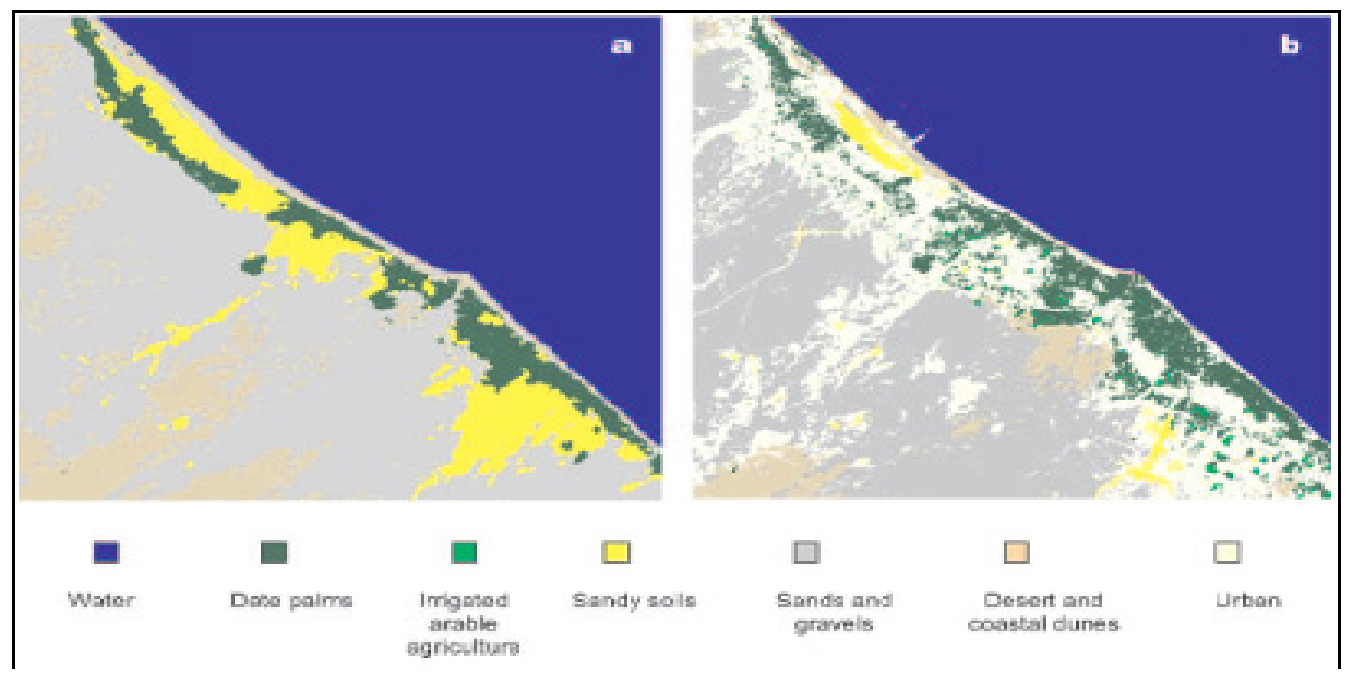

Figure 11. Supervised Classifications in Sohar, (a) Landsat MSS in 1978 (b) Landsat ETM in 2000 (Harris, 2003). 


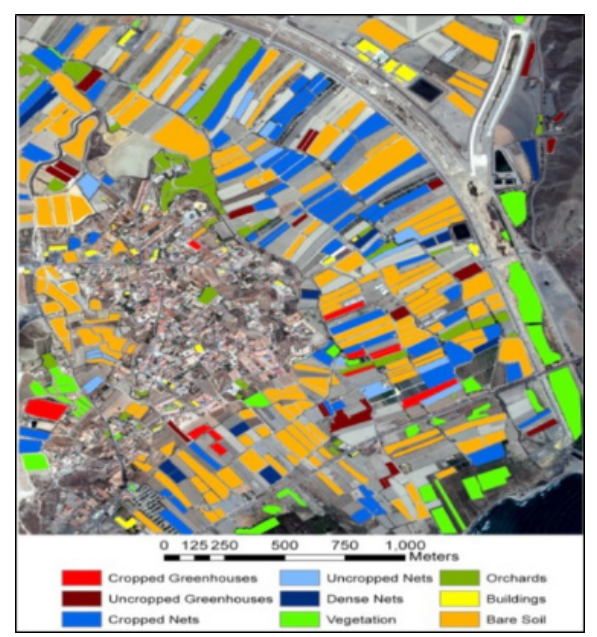

Figure 12. Nine classes assigned for all objects based on aerial PNOA (Spanish Programme of Aerial Ortho-photography) ortho-image (Aguilar et al., 2014).

plastic greenhouses of Almeria in Spain. Eight images were acquired between May and November 2013 from Landsat 8 Operational Land Imager (OLI) where OBIA and decision tree (DT) classifier applied to these images. In addition, a single WV-2 multi-temporal satellite imagery was applied as a data source. Both types of images were utilized to derive spectral information, vegetation indices (VI) and textural features which were already be- imageries. In another study, the accuracy of RS reached 95.9\% in mapping greenhouses with Landsat TM imagery in Qingzhou, China (Geng-Xing et al., 2004).

In Oman, the number of greenhouses increased by almost 40\% annually between 2001 and 2005 (Al-Kiyumi, 2009; Al-Sadi et al., 2007). However, no studies have been done in utilizing RS techniques for identifying and mapping greenhouses or studying the temporal distribution of CEA and the external factors affecting such distribution such as groundwater salinity in the Sultanate. Therefore, a need for such a study is essential to update the status of CEA and all relevant aspects.

\section{Applications of GIS and RS in agriculture}

RS and GIS data are widely utilized in mapping and managing natural resources and building environmental models (Sajjad et al., 2015). For instance, Saleh et al. (2015) evaluated land resources (e.g. soil quality and water availability) for potential agricultural practices using RS and GIS techinques in El-Galaba basin, Eygpt. Similarly, another study used RS and GIS in the assessment of land cover and soil quality (Obade and Lal, 2013). Shalaby and Tateishi (2007) investigated land cover and land use changes in Egypt. RS and GIS were also used to detect changes of forest cover in Tehsil Barawal, Pakistan for 2000 and 2012 (Figure 14) (Sajjad et al., 2015). In another study, Jha et al. (2007) conducted a review for using RS and GIS tools for the development and management
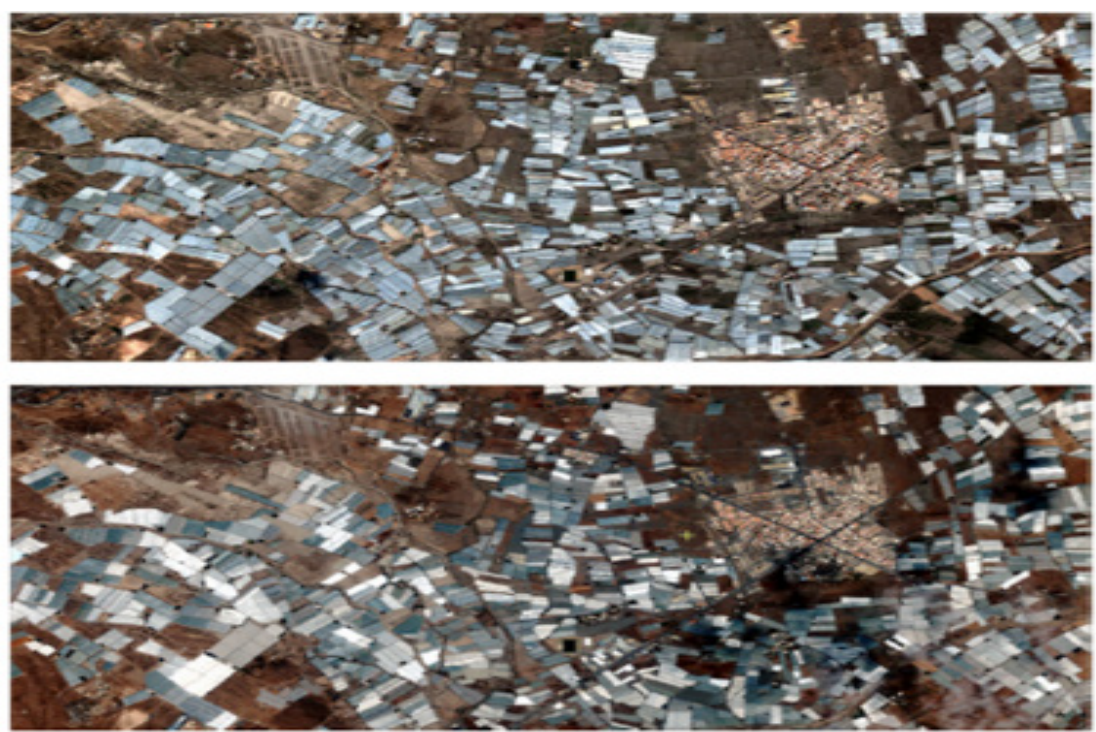

Figure 13. Study area from two different Satellites: QuickBird (top) and IKONOS (bottom) (Agüera et al., 2008).

ing segmented to detect the most popular crops cultivated in greenhouses of the study area (pepper, tomato, aubergine and cucumber). The overall classification accuracy was $81.3 \%$ for the whole series of Landsat 8 OLI of groundwater. Jiménez-Bello et al. (2012) used RS and GIS tools for irrigation management of citrus trees in Southwest Europe. Another study presented the use of Landsat method (which combines GIS and RS) to esti- 

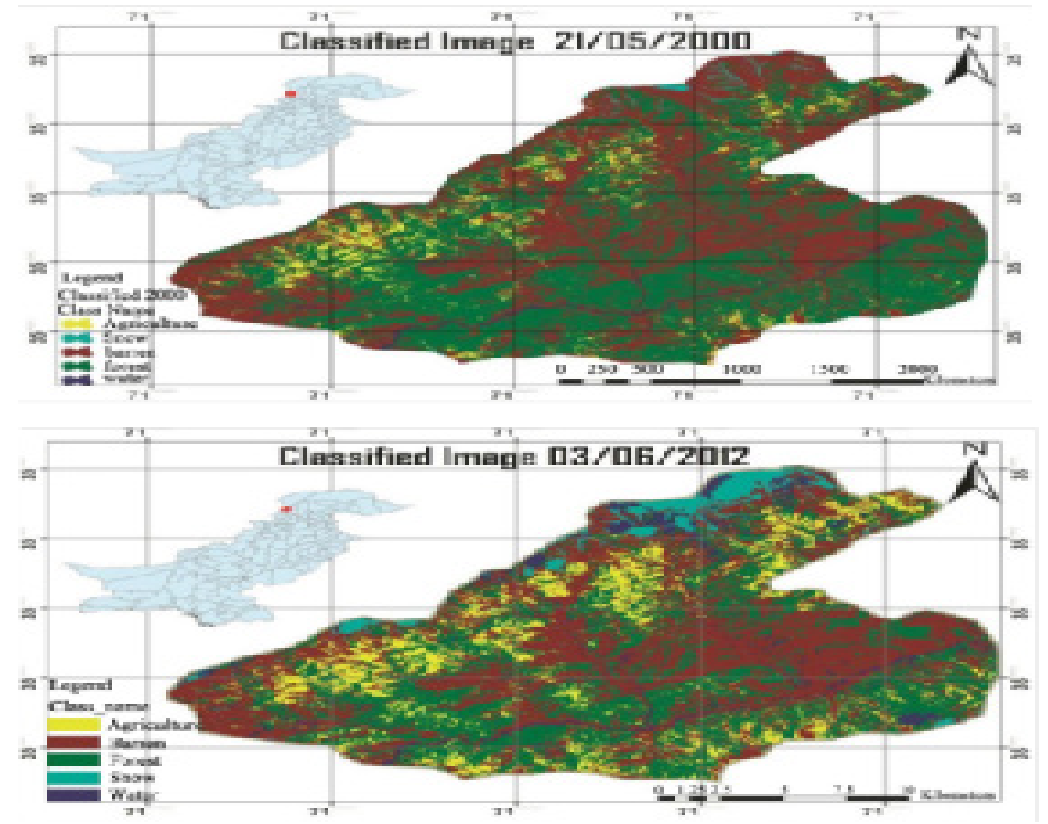

Figure 14. Classified images for the two years: 2000 (above) and 2012 (below) (Sajjad et al., 2015).

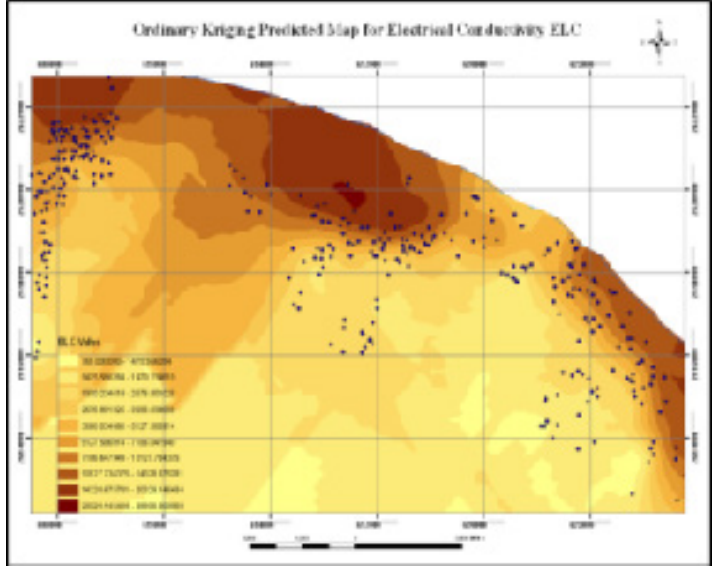

Figure 15. Map of interpolated EC values (MS/cm) (AlRawas and Valeo, 2012).

mate the exposure of agricultural pesticides on human health in USA (VoPham et al., 2015; Ward et al., 2000).

In Oman, GIS and RS techniques have been used to map the temporal changes of soil salinity for 1991 and 2005 in Al-Rumais area, Barka (Al-Mulla and Al-Adawi, 2009). In this study, two satellite imageries were re-projected and geo-referenced and thus, soils affected with salinity were identified and classified. Results showed a high potential of utilizing GIS and RS techniques due to their accuracy, labour saving and cost effectiveness. AlRawas and Valeo (2011) investigated quality of groundwater and pollution sources in As' Seeb area by means of RS, GIS techniques and spatial data analysis. In this study, 335 water samples were collected from the study area. Levels of Nitrate $\left(\mathrm{NO}_{3}\right)$, acidity $(\mathrm{pH})$ and Electrical Conductivity (EC) were analysed and compared to the Omani Standards (MOCI, 2006) and WHO standards for drinking water. Results revealed that all water wells were unsuitable for drinking (beyond Omani standards) because EC values were greater than $4000 \mathrm{MS} / \mathrm{cm}$ in farms close to sea because of over pumping (Figure $15)$ yet, $\mathrm{pH}$ values were within Standards $(6.5-8)$. The percentage of samples that exceeded the allowable concentration levels of $\mathrm{NO}_{3}(>50 \mathrm{mg} / \mathrm{L}$ ) was $23.28 \%$. These levels were originated from populated areas and near to the drainage system which is affected by landfill location of As' Seeb area. The presence of septic tanks and proximity to the landfill were the two major reasons for the increase of $\mathrm{NO}_{3}$. The study is beneficial in providing an overview of the spatial assessment of groundwater quality in As' Seeb city. In another study, GIS and RS techniques were utilized to identify the vegetative cover using satellite imageries in Dhofar, Oman (Al-Awadhi et al., 2011). Three approaches were studied: NDVI, supervised classification and unsupervised classification. Results reaveled that large variations in calcuating the total areas of vegeation among the three approaches. Yet, NDVI was the best approach compared to other approaches since it was closer to visual comparsions.

\section{Applications of GIS and RS in CEA}

RS satellites have the capability of recording environmental information at a fast rate and economical scale for various purposes. GIS can combine these data with other spatial data (e.g. maps) and non-spatial data (e.g. text or tables) to simplify new forms of analyses (Ehlers, 


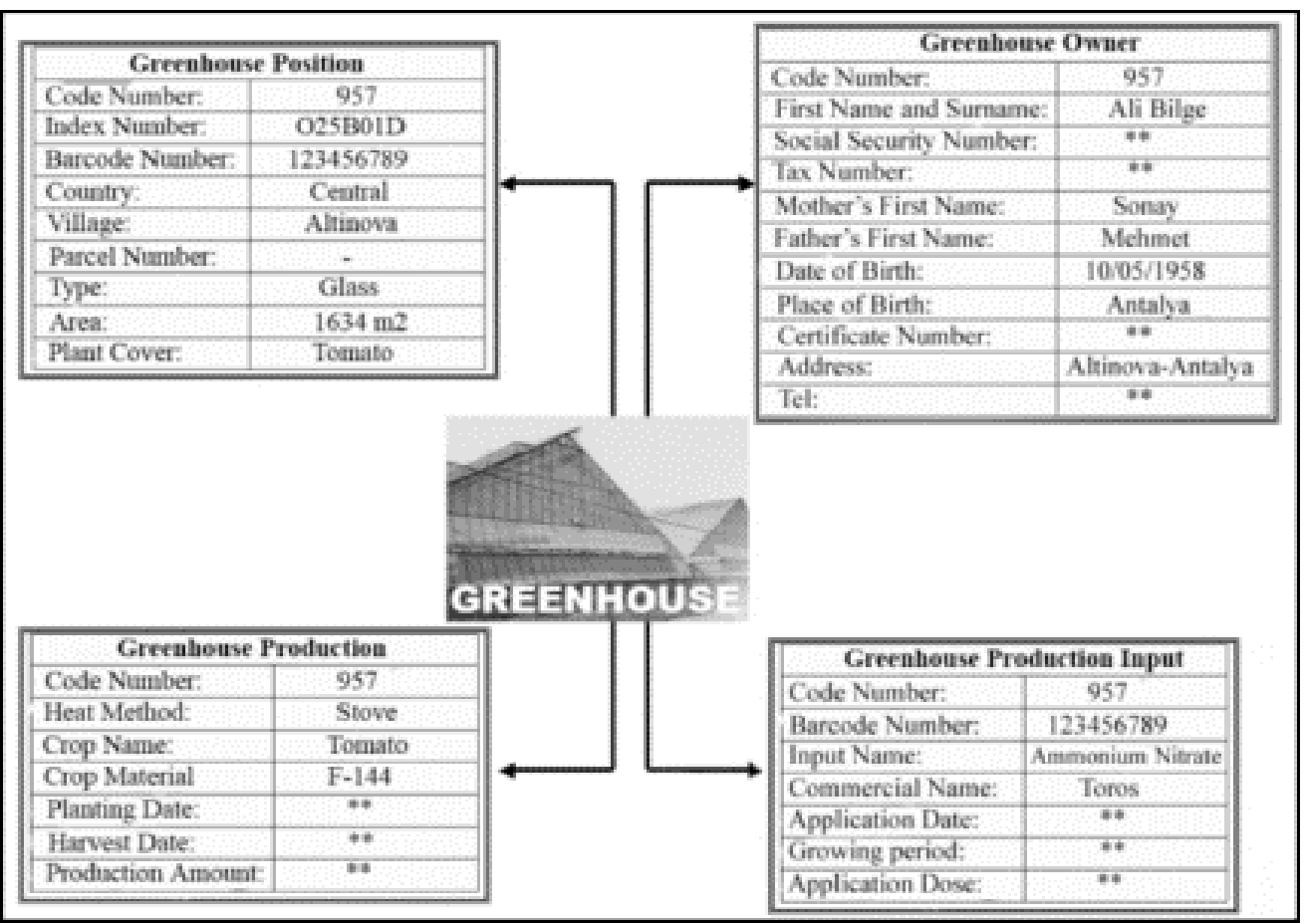

Figure 16. An example of DBMS for a greenhouse, (Sönmez and Mustafa, 2006).

1996). The integration of GIS and RS becomes very helpful (Merchant and Narumalani, 2009). Sönmez and Mustafa (2006) conducted a study to generate a new database system for greenhouses using GIS and RS techniques of Antalya, Turkey, as an effort to determine and register the agricultural resources for the European Union Common Agricultural Policy (EUCAP). Pan-Sharpened IKONOS satellite image was used to determine the type of greenhouses (e.g. glass or plastic greenhouses). Within GIS environment, the Database Management system (DBMS) was created for each greenhouse in the region including position, number, area and type of greenhouses, information about owner, production input and amount of production (Figure 16). Results concluded that the accuracy of using GIS and RS technologies was high (97\% for plastic greenhouses and $96.1 \%$ for glass greenhouses). Also, DBMS provided a reliable source for statistical data. Both technologies were capable in creating databases which were reliable with European Union and other international standards.

In another study, GIS and RS techniques were utilized to determine the negative environmental effects on air, water cycle and agricultural soil under plastic protected cultivation and also to determine the aesthetic distortion in rural areas along the coast of Jonian Sea, Southern Italy (Picuno et al., 2011), (Figure 17). The analysis was carried on multi-temporal Landsat TM images with supervised classification, image processing, GIS tools and vectorialization. Results revealed a method of auto-detection for the plastic covers used in CEA. Furthermore, a concept of "threshold" limit of the quantity of plastic covers was suggested. The possible adjustment of colour and texture of the cladding material was also evaluated. Similar study was done for the environmental effects of crop-shelter by utilizing landscape indicators, RS imageries and GIS analysis (Arcidiacono and Porto, 2010c). Moreover, Arcidiacono and Porto (2010b) built a model

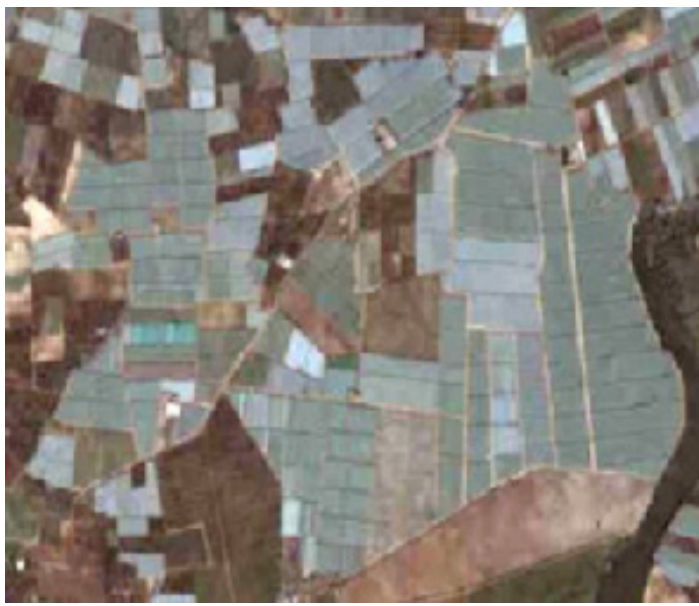

Figure 17. A view of plastic film that covered the agricultural land (Picuno et al., 2011). 
for managing the spatial development of crop-shelter using RS imageries, GIS and spatial indicators in Italy.

In Oman, the Agricultural Census is taking place every 10 years to provide updated statistical data on the agricultural sector components (MAF, 2013). Although the number of greenhouses keeps on growing at rapid rates, there has been no single study that integrated the use of GIS and RS in CEA. So, there is a need for similar studies integrating the use of RS and GIS in order to acquire a consistent statistical data about CEA and all relevant aspects. Consequently, such information may help to increase the income of farmers and food security of Oman.

\section{Conclusion}

In this review, an attempt has been done to highlight the previous inventory work done by scientists and researchers. GIS is one of the powerful techniques in capturing, storing, retrieval, displaying and analysing spatial data. It has a capability of mapping, solving problems, planning, managing, and taking decisions and predications. GIS was utilized in many studies within agricultural fields. In Oman, it has been used only to study the greenhouse distribution and the spatio-temporal dynamics of land use changes affected by external pressures in northern Oman. RS is another useful technique utilized progressively in a variety of agricultural applications around the world. Regarding the CEA in Oman, no studies have been done in utilizing RS techniques for identifying and mapping greenhouses or studying the temporal distribution of CEA and the external factors affecting such distribution such as groundwater salinity. The integration of GIS and RS is very helpful and their data are widely utilised in mapping, managing natural resources and building environmental models. In CEA, satellite imageries and GIS tools were used for generating DBMS, mapping and identifying greenhouses. In Oman, there has been no single study that applied the integration of both techniques. So, a need for a similar study is necessary to acquire a consistent statistical data about CEA and all relevant aspects. This could probably help increasing the income of farmers and food security of Oman. Multi-criteria Evaluation in GIS environment could provide a trade-off analysis for CEA land planning with high ecosystem service value. This platform of trade-off analysis for land suitability analysis could generate different scenarios using spatial and economic information. This approach could be a robust tool for government to achieve agricultural sustainability and adopting effective pathways for better management for natural resources.

\section{Acknowledgement}

sincere thanks to The Research Council, Oman for funding this work through an open grant research fund (project code: RC/AGR/SWAE/15/01).

\section{Funding}

This work received a research fund from The Research Council, Oman through project number RC/AGR/ SWAE/15/01.

\section{References}

Agüera F, Aguilar FJ, Aguilar MA. (2008). Using texture analysis to improve per-pixel classification of very high resolution images for mapping plastic greenhouses. ISPRS Journal of Photogrammetry and Remote Sensing 63(6): 635-646.

Agüera F, Liu JG. (2009). Automatic greenhouse delineation from quickbird and ikonos satellite images. Computers and Electronics in Agriculture 66(2): 191-200.

Aguilar MA, Bianconi F, Aguilar FJ, Fernández I. (2014). Object-based greenhouse classification from geoeye- 1 and worldview-2 stereo imagery. Remote Sensing 6(5): 3554-3582.

Aguilar MA, Vallario A, Aguilar FJ, Lorca AG, Parente C. (2015). Object-based greenhouse horticultural crop identification from multi-temporal satellite imagery: A case study in almeria, spain. Remote Sensing 7(6):7378-7401.

Al-Awadhi T, Al-Shukili A, Al-Amri Q. (2011). The use of remote sensing and geographical information systems to identify vegetation: The case of dhofar governorate (oman). http://www.isprs org/proceedings/2011 (accessed on September 10, 2011)

Al-Awadhi T, Mansour S. (2015). Spatial assessment of water quantity stress in sultanate of oman provinces: A gis based analysis of water resources variability. Journal of Geographic Information System 7(06): 565-579.

Al-Barwani A, Helmi T. 2006. Seawater intrusion in a coastal aquifer: A case study for the area between seeb and suwaiq in the sultanate of oman. Agricultural and Mar Sciences 11: 55-69.

Al-Habsi R. (2015). Gis-linked computer stimulation model for wheat seed emergence prediction in oman. [Sultanate ofOman]:Sultan Qaboos University, Oman.

Al-Ismaili AM, Al-Mezeini NK, Jayasuriya PH. (2017). Controlled environment agriculture in oman: Facts and mechanization potentials. Agricultural Mechanization in Asia. Africa and Latin America 48(2): 45-51.

Al-Ismaili AM, Jayasuriya H. (2016). Seawater greenhouse in oman: A sustainable technique for freshwater conservation and production. Renewable and Sustainable Energy Reviews 54: 653-664.

Al-Kiyumi KSM. (2009). Greenhouse cucumber production systems in oman: A study on the effects of cultivation practices on crop diseases and crop yields. University of Reading Publication, UK. 
Al-Mulla Y. (2010). Salinity mapping in oman using remote sensing tools: Status and trends. Published in the Monograph on Management of Salt-Affected Soils and Water for Sustainable Agriculture. Mushtaque A, Al-Rawahi SA, Hussain N. eds. Sultan Qaboos University, Oman, p. 17-24.

Al-Mulla Y, Al-Adawi S. (2009). Mapping temporal changes of soil salinity in al-rumais region of oman using geographic information system and remote sensing techniques. Paper presented at: ASABE Annual International Meeting. At Reno, NV, US.

Al-Rawas GA, Valeo C. (2011). Spatial assessment of water quality data in a'seeb area, oman using gis. Magazine Geotunis Org, https://www.geosp.net/wp-content/uploads/2012/11 (accessed 17/11/12).

Al-Sadi A, Drenth A, Deadman M, De Cock A, Aitken E. (2007). Molecular characterization and pathogenicity of pythium species associated with damping】off in greenhouse cucumber (cucumis sativus) in oman. Plant Pathology 56(1): 140-149.

Alavipanah SK, Goossens R. (2001). Relationship between the landsat tm, mss data and soil salinity. Journal of Agricultural Science and Technology 3(2): 101-111.

Alhammadi MS, Glenn EP. (2008). Detecting date palm trees health and vegetation greenness change on the eastern coastoftheunitedarabemiratesusingsavi.International Journal of Remote Sensing 29(6): 1745-1765.

Allbed A, Kumar L. (2013). Soil salinity mapping and monitoring in arid and semi-arid regions using remote sensing technology: A review. Advances in Remote Sensing: 2(4): 373-385.

Allbed A, Kumar L, Aldakheel YY. (2014). Assessing soil salinity using soil salinity and vegetation indices derived from ikonos high-spatial resolution imageries: Applications in a date palm dominated region. Geoderma 230: 1-8.

Arcidiacono C, Porto SM. (2010a). Classification of crop-shelter coverage by rgb aerial images: A compendium of experiences and findings. Journal of Agricultural Engineering 41(3): 1-11.

Arcidiacono C, Porto SMC. (2010b). A model to manage crop-shelter spatial development by multi-temporal coverage analysis and spatial indicators. Biosystems Engineering 107(2): 107-122.

Arcidiacono C, Porto SMC. (2010c). A set of landscape indicators to describe environmental impacts of crop-shelter coverage. Paper presented at: XXVIII International Horticultural Congress on Science and Horticulture for People (IHC2010): International Symposium on on Advances in Ornamentals, Landscape and Urban Horticulture, Lisbon, Portugal.

Arcidiacono C, Porto SMC. (2007). Image processing for the classification of crop shelters. Paper presented at: International Symposium on High Technology for
Greenhouse System Management: Greensys 2007, Naples, Italy.

Behrendt S, zum Felde A, De Langhe E, Al Khanjari S, Brinkmann K, Buerkert A. (2015). Distribution and diversity of banana (musa spp.) in wadi tiwi, northern oman. Genetic Resources and Crop Evolution 62(8): 1135-1145.

Bhagat R, Singh S, Sood C, Rana R, Kalia V, Pradhan S, Immerzeel W, Shrestha B. (2009). Land suitability analysis for cereal production in himachal pradesh (india) using geographical information system. Journal of the Indian Society of Remote Sensing 37(2): 233-240.

Bhatta B. (2011). Remote sensing and gis. Oxford University Press, USA.

Campbell JB, Wynne RH. (2011). Introduction to remote sensing. Guilford Press.

Chiranjit S, Kishore CS. (2016). Land suitability evaluation criteria for agricultural crop selection: A review. Agricultural Reviews 37(2): 125-132.

Chivasa W, Mutanga O, Biradar C. (2019). Mapping land suitability for maize (zea mays l.) production using gis and ahp technique in zimbabwe. South African Journal of Geomatics 8(2): 265-281.

Crifasi G, Grassa F, Scrofani M. (2002). Validity of geographic information systems (gis) applied to protected cultivations. In vi international symposium on protected cultivation in mild winter climate: Product and Process Innovation 614 (pp. 41-46)..

Davis BE. (1996). Gis: A Visual Approch. Onword Press, USA.

Dawbin KW, Evans JC. (1988). Large area crop classification in new south wales, australia, using landsat data. International Journal of Remote Sensing 9(2): 295-301.

Deadman ML, Al-Sadi AM, Al-Wardi MM, Al-Kiyumi KS, Deadman W, Al Said FA. (2016). Spatio-temporal dynamics of land use changes in response to external pressures in oman: Greenhouse cropping as an example. Journal of Agricultural and Marine Sciences 21: 33-46.

Ehlers M. (1996). Remote sensing and geographic information systems: Advanced technologies for environmental monitoring and management. Remote sensing and gis for site characterization: Applications and Standards. ASTM International, Pennsylvania, USA.

Elhaddad A, Garcia L. (2006). Detecting soil salinity levels in agricultural lands using satellite imagery. In proceedings of the american society for photogrammetry and remote sensing annual conference, Reno, Nevada,

Gastli A, Charabi Y. (2010). Siting of large pv farms in al-batinah region of oman. In 2010 IEEE International Energy Vonference, 18-22 December 2010, Manama, Bahrain. 
Geng-Xing Z, Jing L, Tao L, Yu-De Y, Warner T. (2004). Utilizing landsat tm imagery to map greenhouses in qingzhou, shandong province, china. Pedosphere 14(3): 363-369.

Harris R. (2003). Remote sensing of agriculture change in oman. International Journal of Remote Sensing 24(23): 4835-4852.

Hedia RM, Elkawy ORA. (2016). Assessment of land suitability for agriculture in the southeastern sector of siwa oasis. Alexandria Science Exchange Journal 37(4): 771-780.

Helmy MA, Eltawil MA, Abo-shieshaa RR, El-Zan NM. (2013). Enhancing the evaporative cooling performance of fan-pad system using alternative pad materials and water film over the greenhouse roof. Agricultural Engineering International: CIGR Journal 15(2): 173-187.

Hiskakis M, Briassoulis D, Babou E, LiantzasK.(2007).Agricultural plastic waste mapping in greece. In international symposium on high technology for greenhouse system management: Greensys 2007 801, Naples, Italy.

Jamrah A, Al-Futaisi A, Rajmohan N, Al-Yaroubi S. (2008). Assessment of groundwater vulnerability in the coastal region of oman using drastic index method in gis environment. Environmental Monitoring and Assessment. 147(1-3): 125-138.

Jayasuriya H, Al-Wardy M, Al-Adawi S, Al-Hinai K. (2014). Gis mapping of soil compaction and moisture distribution for precision tillage and irrigation managementer title. Paper presented at: The 12th International Conference on Precision Agriculture. At Sacramento, California, USA.

Jha MK, Chowdhury A, Chowdary VM, Peiffer S. (2007). Groundwater management and development by integrated remote sensing and geographic information systems: Prospects and constraints. Water Resources Management 21(2): 427-467.

Jiménez-Bello M, Ruiz L, Hermosilla T, Recio J, Intrigliolo D. (2012). Use of remote sensing and geographic information tools for irrigation management of citrus trees. The Use of Remote Sensing and Geographic Information Systems for Irrigation Management in Southwest Europe CIHEAM.147-159.

Jinguo Y, Wei W. (2004). Identification of forest vegetation using vegetation indices. Chinese Journal of Population Resources and Environment 2(4): 12-16.

Kumar KS, Tiwari KN, Jha MK. (2009). Design and technology for greenhouse cooling in tropical and subtropical regions: A review. Energy and Buildings. 41(12): 1269-1275.

MAF. (2013). Agricultural census report 2012/2013 Muscat, Oman: Ministry of Agricultural and Fisheries, Oman.
Manyong VM, Legg C, Mwangi M, Nakato V, Coyne D, Sonder K, Abele S. (2008). The potential benefits of gis techniques in disease and pest control: An example based on a regional project in central africa. In: iv international symposium on banana: International conference on banana and plantain in africa: Harnessing international 879, Mombasa, Kenya.

Matsuoka M, Nagare H, Fujiwara T. (2015). Simulation of the collection of catch crops for the recovery of agricultural resources using geographic and statistical data. Transactions in GIS, Transactions in GIS. 20(2): 221-239.

Merchant JW, Narumalani S. (2009). Integrating remote sensing and geographic information systems. SAGE Publications Ltd: London, UK.

Mishra AK, Deep S, Choudhary A. (2015). Identification of suitable sites for organic farming using ahp \& gis. The Egyptian Journal of Remote Sensing and Space Science 18(2): 181-193.

MOCI. (2006). Omani standard no. 8/2006 for unbottled drinking water, Ministry of Commerce, Oman.

Muscat, Oman: Ministry of Commerce and Industry, General Directorate of Specifications and Measurements, Oman.

Obade VP, Lal R. (2013). Assessing land cover and soil quality by remote sensing and geographical information systems (gis). CATENA 104: 77-92.

Olaniyi AO, Ajiboye AJ, Abdullah AM, Ramli MF, Sood AM. (2015). Agricultural land use suitability assessment in malaysia. Bulgarian Journal of Agricultural Science 21(3): 560-572.

Parthasarathy U. (2010). Importance of gis in agriculture. Financing Agriculture Publisher, Bombay, India.

Picuno P, Tortora A, Capobianco RL. (2011). Analysis of plasticulture landscapes in southern italy through remote sensing and solid modelling techniques. Landscape and Urban Planning 100(1-2): 45-56.

Rajendran S, Al-Sayigh AR, Al-Awadhi T. (2016). Vegetation analysis study in and around sultan qaboos university, oman, using geoeye- 1 satellite data. The Egyptian Journal of Remote Sensing and Space Science 19(2): 297-311.

Reshmidevi TV, Eldho TI, Jana R. (2010). Knowledge-based model for supplementary irrigation assessment in agricultural watersheds. Journal of Irrigation \& Drainage Engineering 136(6): 376-382.

Rhee J, Im J, Carbone GJ. (2010). Monitoring agricultural drought for arid and humid regions using multi-sensor remote sensing data. Remote Sensing of Environment 114(12): 2875-2887.

Romano G, Dal Sasso P, Liuzzi GT, Gentile F. (2015). Multi-criteria decision analysis for land suitability mapping in a rural area of southern italy. Land Use Policy 48: 131-143. 
Sadat-Noori S, Ebrahimi K, Liaghat A. (2014). Groundwater quality assessment using the water quality index and gis in saveh-nobaran aquifer, iran. Environmental Earth Sciences 71(9): 3827-3843.

Sahoo R, Ray S, Manjunath K. (2015). Hyperspectral remote sensing of agriculture. Current Science 108(5): 848-859.

Sajjad A, Hussain A, Wahab U, Adnan S, Ali S, Ahmad Z, Ali A. (2015). Application of remote sensing and gis in forest cover change in tehsil barawal, district dir, pakistan. American Journal of Plant Sciences 6(9): 1501-1508.

Saleh AM, Belal AB, Mohamed ES. (2015). Land resources assessment of el-galaba basin, south egypt for the potentiality of agriculture expansion using remote sensing and gis techniques. The Egyptian Journal of Remote Sensing and Space Science 18(1, Supplement 1): S19-S30.

Shalaby A, Tateishi R. (2007). Remote sensing and gis for mapping and monitoring land cover and land-use changes in the northwestern coastal zone of egypt. Applied Geography 27(1): 28-41.

Sönmez NK, Mustafa S. 2006. Use of remote sensing and geographic information system technologies for developing greenhouse databases. Turkish Journal of Agriculture and Forestry 30(6): 413-420.

Soomro TR. (2015). Gis enabling smart agriculture. In: Rehman A-u, editor. Smart Agriculture: An Approach towards Better Agriculture Management. Foster City, USA: OMICS Group eBooks. p. 61-66.

Tarantino E, Figorito B. (2012). Mapping rural areas with widespread plastic covered vineyards using true color aerial data. Remote Sensing 4(7): 1913-1928.

Tenkorang F, Lowenberg-DeBoer J. (2008). On-farm profitability of remote sensing in agriculture. Journal of Terrestrial Observation 1(1):50-59.

Usery EL, Pocknee S, Boydell B. (1995). Precision farming data management using geographic information systems. Photogrammetric Engineering and Remote Sensing. 61(11): 1383-1391.
Uyan M. (2013). Gis-based solar farms site selection using analytic hierarchy process (ahp) in karapinar region, konya/turkey. Renewable and Sustainable Energy Reviews 28: 11-17.

VoPham T, Wilson JP, Ruddell D, Rashed T, Brooks MM, Yuan J-M, Talbott EO, Chang C-CH, Weissfeld JL. (2015). Linking pesticides and human health: A geographic information system (gis) and landsat remote sensing method to estimate agricultural pesticide exposure. Applied Geography 62: 171-181.

Wang G, Weng Q. (2013). Remote sensing of natural resources. CRC Press, Boca Raton, FL.

Ward MH, Nuckols JR, Weigel SJ, Maxwell SK, Cantor KP, Miller RS. (2000). Identifying populations potentially exposed to agricultural pesticides using remote sensing and a geographic information system. Environmental Health Perspectives 108(1): 5-12.

Wilson JP. (1999). Local, national, and global applications of gis in agriculture. Geographical Information Systems: Principles, Techniques, Management, and Applications, Publisher, Ciry, 981-998.

Wu BM, van Bruggen AHC, Subbarao KV, Pennings GGH. 2001. Spatial analysis of lettuce downy mildew using geostatistics and geographic information systems. Phytopathology. 91(2):134-142.

Yang D, Chen J, Zhou Y, Chen X, Chen X, Cao X. (2017). Mapping plastic greenhouse with medium spatial resolution satellite data: Development of a new spectral index. ISPRS Journal of Photogrammetry and Remote Sensing 128: 47-60.

Yarilgac T. (2012). The use of geographic information systems (gis) in fruit growing. Journal of Science and Technology 2(1): 71-80.

Yu B, Song W, Lang Y. (2017). Spatial patterns and driving forces of greenhouse land change in shouguang city, china. Sustainability 9(3): 359-374. 